\title{
El vacío milagroso: sobre la presencia del cine en la escritura de Mario Bellatin
}

Juan Pablo Cuartas ${ }^{1}$

\section{LAS RELACIONES DEL CINE CON LA LITERATURA DE MARIO BELLATIN SON OBLICUAS E INTERESADAS. ${ }^{2}$ LOS $^{2}$} nombres de Bela Tarr, David Lynch o Tarkovski, por ejemplo, emergen cada tanto en su escritura como vidas ejemplares dedicadas a la fervorosa y paciente labor de construir películas. Estos anacoretas del cine están absorbidos por su arte y, al menos según la información que nos llega, todas sus preocupaciones se organizan en torno a hacer películas, dando por resultado dos cosas: un sistema creativo a partir de unos pocos elementos recursivos y un régimen de vida que sin llegar al ascetismo se orienta fuertemente a la creación. Así, se dice que Bela Tarr "es un cineasta enteramente absorbido por su arte”; ${ }^{3}$ también se conocen las declaraciones de Tarkovski, para quien "un artista de verdad sólo tiene derecho a una actividad creativa si para él es una necesidad vital. Si esa creación es no sólo una actividad casual, secundaria, sino la única forma de existencia de su yo, uno creativo"; ${ }^{4}$ y Lynch, por su parte, dedica su vida a la pintura, el diseño de muebles, obras de cerámica, compone su propia música, realiza cortos de animación y hasta experimenta con la manipulación digital de imágenes fotográficas. ${ }^{5}$

El fervor de Bellatin por estos creadores está conjugado, entonces, con cierta pedagogía que se desprende de una vida dedicada al arte, ${ }^{6}$ interés que el escritor hará metodología cuando en el año 2000 funde una Escuela Dinámica de Escritores donde los alumnos aprenden a narrar, no de maestros escritores, sino de arquitectos,

\footnotetext{
${ }^{1}$ Doctorando de la Facultad de Humanidades y Ciencias de la Educación (UNLP) en cotutela con la Université de Poitiers.

${ }^{2}$ Nos referimos a las referencias al cine tanto en su literatura como en declaraciones personales realizadas en entrevistas y textos de corte autobiográfico. Bellatin ha realizado, además, incursiones en el trabajo con imágenes cinematográficas. Un resumen de esta trayectoria se encuentra en Cherri, C. Cine y literatura en América Latina. Las intervenciones de Mario Bellatin. Boletim de pesquisa nelic, Florianópolis, v. 15, n. 24, 2015.

${ }^{3}$ RANCIÈRE, J. Bela Tarr. Después del final. Buenos Aires: El cuenco de plata, 2013, p. 11.

${ }^{4}$ TARKOVSKi, A. Esculpir en el tiempo. Reflexiones sobre el arte, la estética y la poética del cine. Madrid: Ediciones Rialp, S.A., 2002 [1985], p. 215.

${ }^{5}$ RODLEY, C. Lynch por Lynch. Buenos Aires: El cuenco de plata, 2017, p. 14.

6 "Leo mucho y poco, depende de las épocas, de manera confusa, salteada, casi siempre sólo comienzos. En mi casa se puede encontrar una gran cantidad de libros tirados y abiertos por todas partes. Ahora, si pienso en qué autores leo con interés en diálogo con mis ficciones, diría que eso me ocurre de manera más clara con creadores de otras artes. Con teóricos del teatro, del cine. Artistas visuales, arquitectos. Es mucho más provechoso buscar los puntos de unión que puede tener mi trabajo con otras disciplinas que no sea la literatura. Han sido más importantes mis pesquisas en los universos de Kantor, Brook, Beuys, Tarkovsky, Barney, Piano, por nombrar algunos, que en los exclusivos de la escritura.” BELLATIN, M. Señas particulares. Página 12. Entrevistador: Patricio Lennard, 2006, sp.
} 
fotógrafos y representantes de otras disciplinas. ${ }^{7}$ El aprendizaje es acéfalo, incalculable, y la escritura finalmente sucede en otra escena: los estudiantes pueden escribir en un gabinete privado, pero no en el espacio de la escuela. ${ }^{8}$

Este tipo de relación es la que Bellatin establece con los cineastas mencionados. No es el enciclopedismo en torno a ciertas películas, como suele practicar el cinéfilo copioso, sino que es la insistencia en el encuentro con vidas dedicadas al arte y con ciertas imágenes y residuos de aquellas películas que obseden al escritor. Se puede ver en la mención que hace de aquellos cineastas en entrevistas, pero también en el fervor por la huella menor de una imagen, un fotograma, como es el caso de cierta imagen de la película Stalker, de Tarkovski, que circula por sus manuscritos así como en las redes sociales del escritor mexicano. Salvando esto, este tipo de cine tiene una presencia no siempre discernible en la escritura del autor. Después de todo, ¿quién puede ubicar con precisión a Tarr $^{9}$ o a Tarkovski en tal o cual relato bellatiniano, siempre que se conceda que hay un afecto o interés que moviliza al escritor? Como los maestros de la Escuela Dinámica de Escritores, los cineastas enseñan sus trayectos y creaciones cuyas huellas no se hacen manifiestas en la escritura, quedando la sospecha de que esa presencia es nula o que los cineastas permanecen como invisibles e inconcientes andamios que sostienen esa misma escritura. ${ }^{10}$

\footnotetext{
${ }^{7}$ Resuena la pedagogía deleuziana del encuentro con el signo problemático y de las soluciones que se inventan y que comprometen al aprendiz. "Aprender es la palabra que conviene a los actos subjetivos que se realizan frente a la objetividad del problema (Idea); mientras que saber designa únicamente la generalidad del concepto, o la calma posesión de una regla de las soluciones [...] De manera que 'aprender' pasa siempre por el inconsciente, ocurre siempre en el inconsciente, y establece un lazo de profunda complicidad entre la naturaleza y el espíritu [...]¿A partir de qué signos de la sensibilidad, por medio de qué tesoros de la memoria, bajo torsiones determinadas por las singularidades de qué Idea se suscitará el pensamiento? Nunca se sabe por anticipado cómo alguien va a aprender: por qué amores se llega a ser bueno en latín, por qué encuentros se es filósofo, en qué diccionarios se aprende a pensar”. DELEUZE G. Diferencia y repetición. Buenos Aires: Amorrortu, 2009, pp.
} 251-252

${ }^{8}$ Bela Tarr también sostuvo una escuela de cine con presupuestos cercanos a los de la Escuela Dinámica de Escritores. "Ahora estoy seguro de que es imposible enseñar a hacer películas porque todos somos diferentes. En lo que llamábamos nuestra escuela, yo tenía veinte estudiantes de todos los rincones del mundo. Tenía una chica lesbiana japonesa, un coreano, un chico homosexual de Singapur, gente de Colombia, India, Estados Unidos, Islandia. No podía darles una clase y decirles "este es el camino". Había que encontrar el camino de cada uno de ellos, teniendo en cuenta cada experiencia cultural. La cultura de la colombiana era diferente de la del japonés o la del islandés. Cuando trabajábamos juntos se daba el mismo proceso que se aplica a los actores: era preciso hallar la llave para cada uno y ser muy honestos". TARR, B., \& BEDOYA-WILSON, R. La extensión del mirar: entrevista a Béla Tarr. Ventana indiscreta $\mathrm{N}^{\circ} 20$, Lima, 2018, p. 73.

${ }^{9}$ Tarr aparece mencionado en un relato que circula en internet y especialmente vinculado a la idea de "sistema" o de trabajo metódico con su arte. "Pero Mario, Benjamín, da la impresión de que cree que la historia es distinta cuando se trata de un autor extranjero. Pone el caso de Béla Tarr, quien le parece uno de los últimos cineastas a la vieja usanza. Aquellos que mostraban un sistema”. BELLATIN, M. Algo que funciona sin funcionar. diecisiete, 7(7), 2015, sp.

${ }^{10}$ Aquí vale colocar la figura de César Moro. En una entrevista del año 2013, Mario Bellatin confiesa que su relación con este poeta peruano había sido de "orden coyuntural". Bellatin, M. Yo, creo, soy un señor que escribe. (Conrado Chang, entrevistador). Buen salvaje, 2013, sp. La influencia del poeta y pintor surrealista no correría por el lado de la literatura, sino por los compromisos que un sujeto realiza para poder escribir: el escritor en su lucha vital contra todo aquello que obstaculiza la práctica de escritura y que, en muchos casos, coincide con aquello mismo que la posibilita. César Moro, cuya imagen es foto de portada de la cuenta de Facebook de Bellatin desde hace años, se convierte en el primer maestro de lo que llamaríamos una Escuela Dinámica de Escritores personal de Bellatin: si es cierto que "no se debe, no se puede enseñar a escribir" (BELLATIN, M. (coord.) El arte de enseñar a escribir. Santiago de Chile: Fondo de Cultura Económica, 2006b, p. 11), en Moro tenemos avant la lettre a uno de esos maestros que en la Escuela fundada por Bellatin enseñaban a escribir sin hacerlo efectivamente, que 
Con la película Simón del desierto, el nombre de Luis Buñuel ingresa en esta colección evanescente de anacoretas del cine. ${ }^{11}$ En primer lugar, porque la conocida ambivalencia del cineasta español hacia el cristianismo, mezcla de irreverencia y fascinación, tiene ecos en un escritor como Bellatin donde aquella religión se encuentra omnipresente en sus primeras novelas, especialmente en Poeta ciego, que representa "una gran pantomima, una imitación exagerada de la Iglesia, que por un lado exhibe lo cómico y lo bufonesco y por otro, lo trágico y lo terrible". ${ }^{12}$ En segundo lugar, porque Simón del desierto emerge de modo explícito en la superficie textual bellatiniana en un relato que, según veremos, se relaciona con aquella película de una forma que parece oblicua y caprichosa, pero que en realidad es esencial o, para no usar ese término, habrá de ser consecuente, habilitando además un entendimiento más claro de la relación de Bellatin con aquellos cineastas. ${ }^{13}$

"En tu casa habita otro inquilino" de Mario Bellatin ${ }^{14}$ narra la emergencia de un supuesto culto alrededor de una columna, única ruina escenográfica de Simón del desierto, mediometraje que Luis Buñuel rodó en Hidalgo, México. La película, filmada en 1965 y premiada en el Festival de Venecia, transcurre con el personaje principal

enseñaban a escribir de modo coyuntural, no transmitiendo e imponiendo preceptos sino mostrando lo propio a la espera de un efecto en lo impropio, en el otro, el alumno.

${ }^{11}$ La libertad para la creación es la que está en paradójica correlación con esa forma de vida dedicada en reclusión a las películas. Para Buñuel, Simón del Desierto es el hombre más libre del mundo "porque tiene y hace lo que quiere, sin encontrar obstáculos. Está allá arriba en una columna, comiendo lechuga. La libertad total”. DE LA COLINA Y PÉREZ TURRENT. Buñuel por Buñuel. Madrid: Plot Ediciones, 2002, p. 130.

${ }^{12}$ LÓPEZ ALFONSO, F. J. Mario Bellatin, el cuadernillo de las cosas dificiles de explicar. Universidad de Alicante, 2015, p. 50. La definición de imitación cómica y bufonesca de la iglesia en Bellatin recuerda a la parodia de la última cena que Buñuel escenifica en Viridiana (1961). O para el caso que nos ocupa, el milagro que opera Simón en la película: le devuelve las extremidades a un hombre al cual le habían sido amputadas las manos. Dice Buñuel en relación a su concepción ordinaria, normalizada, de los milagros: “¿Qué es lo primero que hace con sus milagrosas manos? Darle un coscorrón a su hija: ‘AAnda, niña, vámonos a casa!” DE LA COLINA Y PÉREZ TURRENT Op. cit. p. 140. Vale anotar el matiz que diferencia a Bellatin, para quien lo cómico suele adquirir las notas más ominosas. Para un análisis de lo cómico y su peso en la constitución del verosímil en Bellatin, me remito a Cuartas, J.P. El realismo cómico de Mario Bellatin: Shiki Nagaoka y el sentido errático. JAIMES, H. (Ed.). Mario Bellatin y las formas de la escritura. UNC Press Books, 2020.

${ }^{13}$ Buñuel cruza de modo transversal el grupo de los anacoretas del cine. Mientras que Tarkovski dice que "se siente plenamente identificado" con Buñuel (IBÍDEM 72), a Lynch se lo asocia mucho al cineasta español por la vena surrealista que aunaría a ambos dos. En Blue velvet (1986), por ejemplo, habría un homenaje explícito a Buñuel cuando el protagonista de la película encuentra en el campo una oreja amputada llena de hormigas en lo que sería un claro reenvío a las hormigas de $E l$ perro andaluz (1929). No obstante, Lynch ha desestimado la influencia. En una visita a Madrid afirmó: "Nunca he visto una película de Buñuel. Pero sé que en sus películas hay hormigas, y también sé que cuando hay orejas humanas en el campo, es muy probable que acaben llegando las hormigas". DE PEDRO, G. David Lynch: "Nunca he visto una película de Buñuel”. $E l$ confidencial, Madrid, 2013, sp. Esta aclaración, que bordea la inocencia y el sentido común, es el efecto consecuente de un artista sistemático y consagrado enteramente a su obra: entre el arte y una vida dedicada a su práctica no hay espacio para las conexiones de la crítica especializada.

${ }^{14}$ BELLATIN, M. "En tu casa habita otro inquilino. El milagro de Buñuel”. Revista de la Universidad de México, 2018, pp. 8387. El relato tiene una versión anterior publicada en el sitio Vice, en el año 2013. La trama no difiere salvo algunas diferencias en cuanto al relato, especialmente en la caracterización de los Devotos de la columna; las divergencias más visibles y significativas son en cuanto a la forma: la escritura se muestra fragmentada y hay constantes intervenciones del escritor consultando a un tercero innominado acerca de la facticidad de lo escrito. Bellatin, M. En tu casa habita otro inquilino, Vice, 2013. Disponible en https://www.vice.com/es/article/wd93pq/en-tu-casa-habita-otro-inquilino-v1n1. 
parado sobre la columna a manera de penitencia mientras es tentado por diferentes personajes demoníacos. ${ }^{15}$ Casi todo el film transcurre en ese espacio. El relato de Bellatin, cuyo nombre viene de la última línea dicha en la película, está construido en torno a esta columna y, como ocurre con otras de sus creaciones, se repite el cruce problemático entre una escritura pensada y construida para sostener la lectura y una escritura fragmentaria cuyos nexos narrativos no son inmediatamente abarcables con la mirada o el pensamiento. Todo el relato tiende a irse por la tangente de los fragmentos repetitivos, aspectos biográficos del autor, fotografías y, en medio de todo eso, la opacidad de una columna en torno a la cual esos relatos inestables se posicionan. El contexto del relato es importante: surgió como parte de una acción artística presentada en el evento "Miracle Marathon", en las Serpentine Galleries de Londres, un ciclo sobre cine y misticismo, donde por 24 horas se escuchó la narración en una suerte de pieza sonora. El relato en cuestión comienza con la "acción conocida como el milagro de Luis Buñuel": los "Devotos de la columna" son refugiados que huyen de un terremoto y que padecen una posesión demoníaca que es combatida por el líder de la hermandad, el "poeta ciego". ${ }^{16}$ Bellatin aparece como personaje: es un escritor que huye de la "Gran Guerra" y que conoce la historia de la columna por el relato de un empleado de su salón de belleza. ${ }^{17}$ En uno de sus paseos junto a sus galgos (algo que el autor hace con frecuencia), encuentra la columna y sobre ella descubre una serie de estampas que tiene la imagen de la columna como centro. En determinado momento, aparece un grupo de "investigadores culturales" que, mediante la ayuda de obreros y vehículos, dinamitan el símbolo de la película con la intención de llevarlo como testimonio al centro de los homenajes que se le organizaban a Buñuel en el Palacio de Bellas Artes. Ocurre el milagro: la columna es dinamitada, se parte en dos, pero debido a su peso no se consigue trasladarla al Palacio de las Bellas Artes. Los integrantes de la cofradía reaccionan abandonado el lugar donde se erigía la columna y se dispersan en distintos puntos, como la ciudad capital o las zonas fronterizas. "Todos, sin embargo, llevan tanto el mensaje como el milagro de la columna mágica, que aparte de haber aparecido de la nada se negó a ser trasladada”. ${ }^{18}$

Hay que destacar en la emergencia de dos objetos que posibilitan la escritura y que, de alguna manera, son efectuados por la misma. Por un lado, está la columna de Buñuel que, en efecto, existe y es un remanente de la

${ }^{15}$ San Simón o Simeón el Estilita o simplemente Simón Estilita, también conocido como Simeón Estilita el Viejo (para diferenciarlo de Simeón Estilita el Joven y Simeón Estilita III), fue un santo asceta cristiano que nació a finales del siglo IV en Cilicia, en la actual costa sur de Turquía. Como penitencia pasó 37 años en una pequeña plataforma sobre una columna ${ }^{2}$

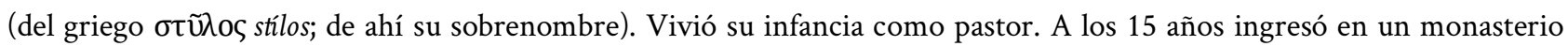
donde aprendió de memoria los 150 salmos de la Biblia, rezándolos cada semana, 21 cada día. Se le considera el inventor del cilicio, un accesorio utilizado para provocar deliberadamente dolor o incomodidad en quien lo viste. Fue expulsado de un monasterio por su rigor absoluto, así que decidió ir al desierto para vivir en continua penitencia. Luego de vivir en una cueva, y a causa de la continua visita de las gentes, decidió que le construyeran una columna de tres metros de altura, luego una de siete y por último pasó a una de 17 metros para vivir subido en ella y alejarse del tráfico humano.

${ }^{16}$ El "poeta ciego" es el líder de otra secta religiosa en la novela homónima Poeta ciego (1998). En esta sexta novela de Bellatin se relata la historia de una organización político-religiosa comandada por un poeta ciego que la rige según preceptos escritos por su propia mano. El asesinato del líder, quien al momento del hecho se encontraba violando esos mismos preceptos, desencadena una lucha por el poder y por la interpretación quasi-legal acerca de la figura del poeta ciego contrapuesto a los mismos principios que estableció.

${ }^{17}$ Referencia a la cuarta novela del autor. Salón de belleza (1994) relata la transformación de un establecimiento de estética en un "moridero", un lugar donde van a internarse quienes padecen de una enfermedad terminal no mencionada. Allí son asistidos, sin intervenir en materia sanitaria, por el estilista que en otros tiempos regenteaba el local.

${ }^{18}$ BELLATIN 2018, p. 87. 
película Simón del desierto. La escritura no va a relatar las peripecias de la columna, sino que va a hilvanar algunas historias alrededor de esa presencia maciza, la columna de estilo romano dejada por Buñuel en el desierto y no, por ejemplo, de cualquier columna, o de una imagen tomada durante el rodaje, sino de una imagen de lo que efectivamente quedó. La presencia de la columna al interior del relato funciona como un punto de llegada y retorno constante, ya que la historia de la columna recomienza en varias ocasiones: por el encuentro de Bellatin y sus galgos, por el testimonio de su empleado en el salón de belleza y cuando afirma que realizará una serie de imágenes para el proyecto "Simón del desierto" al que fue convocado. Por otro lado, tenemos una fotografía de la misma columna: el autor le solicitó a la artista Graciela Iturbide una imagen de la columna, la estampó, y le pidió a vecinos de su vecindario que se dejaran fotografiar junto a la imagen, que pasa a ser, dentro de los parámetros del relato, una "imagen sagrada", mientras que los vecinos se convierten en los "devotos de la columna" del relato. Como afirma Graciela Goldchluk, la imagen fotográfica de la columna, separada de su contexto, va junto a "los rostros de los habitantes del barrio que, en un encuentro insólito, parecen ser puro contexto que repone por azar ese primer encuentro, 'carnavalizando' la situación (la estampa de la columna como la elección del Rey Momo). ${ }^{19}$ La supervivencia de esta columna interrumpiendo el paisaje social no es borradura de la historia sino todo lo contrario, "hace aparecer la historia donde no se la esperaba, ya que es ahí donde sucede, y por eso es importante que los que aparecen en las fotos sean, como en la película Salón de belleza, vecinos que habitan en el radio de una manzana" ${ }^{20}$.

Modificando un poco los términos, puede afirmarse que la columna de Buñuel perseverando en un territorio ya demasiado extraño abre la posibilidad de un tiempo como emergencia y suspensión, y no como continuo con mayúsculas del cual la columna sería una expresión. La emergencia de lo no esperado es, justamente, aquello olvidado que suspende la cronología de lo esperable por la memoria y que llama la atención sobre el sitio donde surge. En este sentido el olvido está reduplicado: la columna misma fue olvidada, pero también su conexión con ese territorio en el cual ahora se levanta haciendo tambalear la lógica de los lugares. ${ }^{21}$ Esto traza una línea de demarcación entre los anacoretas del cine que acompañan en silencio a Bellatin, en especial con Tarkovski. El cineasta ruso considera que el flujo y concreción del tiempo es el principal impulso de su arte, y que la participación del artista, en forma de "cine de autor", consiste en la observación como principal aporte para aquella materialización del tiempo. "La imagen fílmica es, en esencia, la observación de un fenómeno inserto en el tiempo" dice

\footnotetext{
${ }^{19}$ GOLDCHLUK, G. El gran vidrio: un espejo imposible de identidades inexistentes plantado en medio del desierto literario. Deconstrucción del espacio literario en América Latina: 1996-2016. Universidad de Buenos Aires y Universidad de Poitiers, 2019, p 48.

${ }^{20}$ BELLATIN 2018, p. 87.

${ }^{21}$ La figura tutelar aquí es, por supuesto, Walter Benjamin y su desmontaje de aquellos abordajes continuistas de la temporalidad, ante los cuales antepondrá una gramática temporal basada en la suspensión y, como corolario, en una idea del olvido que "no se limita a ser el reverso negativo y relegado de la memoria, sino, más bien, como su más potente condición". ESPINOSA, L.; \& SFERCO, S. La fuerza discontinuante del olvido en la filosofía de Walter Benjamin. Heterotopías, 3(6), 2020, p. 225. El olvido llama la atención sobre el lugar, el espacio, para luego abrir el camino al tiempo. Dice Benjamin: "Se engaña a sí mismo de la mejor manera aquel que sólo realiza el inventario de lo hallado y no puede señalar en el suelo de hoy el lugar preciso en el cual preserva lo antiguo. Así, los verdaderos recuerdos deben proceder menos informando que señalando el lugar exacto en el cual el investigador se apoderó de ellos. Épico y rapsódico en sentido estricto, por lo tanto, el recuerdo real debe al mismo tiempo proporcionar una imagen de aquel que recuerda, como un buen informe arqueológico no sólo debe indicar los estratos de los cuales proceden sus hallazgos, sino sobre todo aquellos otros que debieron ser atravesados antes”. BENJAMIN, W. "Exhumar y recordar” ("Ausgraben und Erinnern“). Gesammelte Schriften. Frankfurt am Main, 1991, p. 400. Traducción de J. A. Ennis para uso de la cátedra de Filología Hispánica, Universidad Nacional de La Plata.
} 
Tarkovski ${ }^{22}$ para establecer, más adelante, que cualquier pulular de objetos y eventos no pueden manifestarse de forma aislada, suspendida. "Ni un sólo objeto "muerto", ni una mesa, una silla, o copa concientemente utilizada en una toma debe ser presentada fuera de ese tiempo, como si fuera símbolo de un tiempo inexistente". ${ }^{23}$ Muy atento a los ejemplos literarios, Tarkovski deja la imagen cinematográfica y localiza un caso en las letras del escritor francés Marcel Proust, quien también intentaba dominar el tiempo como materia artística. El cineasta ruso recuerda aquello que Proust decía de su abuela:

Aun cuando debía de hacer a alguien un regalo útil, cuando tenía que dar un sillón, cubiertos, un bastón, los buscaba "viejos", como si, una vez que su largo desuso hubiese borrado su carácter utilitario, estuviesen más dispuestos a contarnos la vida de la gente de antaño que a servir a las necesidades de nuestra época. ${ }^{24}$

La cuestión localizada en Proust es la vocación del cine para Tarkovski: dominar este nuevo material artístico, el tiempo. Este tiempo esculpido en las cosas se entiende mejor en su película Stalker, donde la cámara se pasea de modo minucioso por despojos humanos acorralados por la naturaleza. Los objetos son en sí mismos y, además, son el tiempo esculpido.

¿Dónde queda parada la columna de Buñuel-Bellatin en esta dualidad material y temporal del universo tarkovskiano? En ningún lado, al menos no en ese esquema temporal. ${ }^{25}$ Porque a diferencia de los objetos del cineasta ruso, la columna involucra una suspensión del tiempo y de su historia. A diferencia de los utensilios de Proust, la columna real no tiene en su materialidad la accidentalidad que la revele como índice necesario de algo mayor (la película de Buñuel), del mismo modo que la columna en la escritura de Bellatin no tiene forma de reenviar a la constatación de que realmente existe una columna de Buñuel y no que, finalmente, todo sea una ficción, una broma del autor (so pena de que se indague por fuera de la lectura, empujado por algún rumor ajeno al pacto de lectura literaria). Los lectores estamos en una situación de indecidibilidad con respecto a la conexión entre la columna y el nombre de Buñuel, empujados a la fe como los Devotos de la columna. De este modo, la dualidad tarkovskiana es reemplazada aquí por una dualidad inherente a la columna, marcada por la ambivalencia y suspensión sobre su procedencia y veracidad (¿existe esa columna o es una más de las bromas bellatinianas? ¿la columna fotografiada es efectivamente esa columna?).

\footnotetext{
${ }^{22}$ IBÍDEM 88.

${ }^{23}$ IBÍDEM 89.

${ }^{24}$ Proust en TARKOVSKI (2002: 80).

25 Aquí nos separamos del Deleuze en sus estudios de cine, para quien la columna funcionaría como "imagen-cristal", compuesta por "la imagen actual del presente que pasa y la imagen virtual del pasado que se conserva: distintas y, sin embargo, indiscernibles, y más indiscernibles cuanto más distintas, pues no se sabe cuál es una y cuál es otra. Es el intercambio desigual, o el punto de indiscernibilidad, la imagen mutua”. DELEUZE, G. La imagen-tiempo. Estudios sobre cine 2. Barcelona: Paidós, 1987, p. 114. Para Deleuze, como para Tarkovski, el objeto-imagen es tiempo, es decir, creación continua, pero efectiva solamente en su división (entre sí mismo y su expresión del tiempo). Para nosotros, y nos gustaría pensar que también para Bellatin, la columna no es ninguna imagen escindida entre dos partes, ella misma -lo actual- y el tiempo pasado -lo virtual. Es, antes bien, un objeto unívoco cuya ligazón con el tiempo o el pasado está vacía, y que si, en todo caso, su singularidad se abreva en cierta conexión (Simón del desierto), ésta viene dada por la novedad actual de la invención-descubrimiento de esa conexión ("En tu casa habita otro inquilino").
} 
Podríamos conformarnos con el relato, la ficción imaginaria, y dejar de lado el asunto. Pero lo cierto es que lo interesante del relato, lo que fascina la mirada es el encuentro con esa columna de Buñuel. Tiene que ser efectivamente la columna de la película Simón del desierto y no un hápax literario o mera ocurrencia del escritor. No obstante, lo significativo está en otro lado: no en el objeto en sí, sino en la ausencia de relación entre semejante columna (que tiene que seguir siendo la de Buñuel) y el contexto que genera a su alrededor (las nuevas poblaciones mexicanas, pero también los devotos de la columna de Bellatin). Ese vacío es explotado por el escritor mexicano, hasta el punto de que efectivamente fotografía a vecinos con una estampa de la columna, como si buscara acorralar por todos los medios la no-relación que, sin embargo, supone el encuentro entre los dos términos. Por eso, visibilizar la supervivencia de esta columna no es tanto un ejercicio de esculpir el tiempo, donde el objeto se desdoblaría para vehiculizar el Tiempo con mayúsculas, sino el acto de mostrar la emergencia de un tiempo menor, local, con minúscula, mediante el encuentro insólito de esa columna de una película de los sesentas y vecinos mexicanos que conviven junto a ella sin participar de una misma temporalidad. Así, la realidad de la columna no reside en el efecto de su comprobación empírica y exterior, sino en el hiato de la ausencia de relación entre la columna y sus demografías contemporáneas. Es, en otros términos, un corte o vacío entre la columna y su territorio, un encuentro que es, a su vez, desencuentro. De este modo, si en efecto se busca constatar la realidad de la columna sin caer en la fe al autor, podemos señalar que no se requiere salir del relato para ello: es la propia forma escritural la que revela lo real de su contenido, ya que el hiato o ausencia de relación entre la columna y su territorio se relaciona con el núcleo central del proyecto escritural bellatiniano. Escribir, para el escritor, es orquestar un careo entre el vacío y la creación. Es lo que llama "escribir sin escribir": volver sobre su escritura para reducirla a su estructura mínima y para que emerjan los vacíos y blancos de papel, condición indispensable para decir lo que las palabras no pueden decir y para toda intervención en el texto de la lectura constitutiva del lector. ${ }^{26}$ Esto supone, para el escritor, una trabajo de desescritura que deje, no obstante, algo en pie, so pena de desbarrancar al terreno de la afasia, de lo insensato, y hasta de cierta experimentación poética, ya que "no es mediante la negación del sentido que se experimenta el vacío, sino mediante el gesto que pretende borrar las fronteras textuales y los márgenes de su convención”. ${ }^{27}$ La "desescritura", entonces, tiene sus límites. Estos últimos son los que Bellatin acorrala en cada escritura, son la frontera que vincula escritura y vacío, que nos hace pensar en una escritura que no persigue ni ocupa el vacío en general, sino que emerge junto a un vacío en particular, el que surge localmente en nuestros precarios campos de sentido compartidos. Por eso Bellatin muestra ese vacío entre columna y nuevas gentes, entre columna e historia (porque no hay Historia, Sentido, ni Vida Impersonal que relacione las partes) por medio de una intervención -escritura y fotografías- que depende de ese vacío y al que señala. ${ }^{28}$

\footnotetext{
26 "Lo de escribir sin escribir es un término con el que trato de situar mi propia escritura. No estoy seguro de lo que es, pero intuyo que tiene que ver con el deseo de dejar una marca utilizando un instrumento mediador - una máquina de escribir, una computadora, un iPhone-, y el escribir sin escribir propiamente dicho tiene que ver con el trabajo de desescritura constante que realizo con los textos que estoy haciendo. Nunca me siento más escritor que cuando voy deshaciendo todo lo escrito hasta dejarlo solo en una suerte de estructura mínima, de carácter de andamio casi, donde me gustaría que cada lector reconstruya su propio libro". BELLATIN, M. “Mario Bellatin se despoja de todo”. La Nación, Buenos Aires, 2017, sp.

${ }^{27}$ VERGARA, P. El vacío como gesto: representación y crisis del sentido en la obra de Mario Bellatin. Revista Laboratorio, (2), 2010, p. 7.

${ }^{28}$ En un sentido más directo podríamos decir que Bellatin puede ver la columna porque escribe como lo hace. Rancière señala algo similar, aunque en su terminología, con respecto al famoso barómetro de Flaubert que Barthes elevara a índice de lo real: "Sin duda el barómetro está en el relato sin intención preconcebida, tan sólo porque el novelista lo "veía" en el momento de
} 
Esto no es el final del asunto, ya que queda el papel del lector o del crítico. Desde este lado nos queda la invención-descubrimiento de nuevos lazos consecuentes entre la columna y la película de Buñuel, así como entre la columna y sus gentes contemporáneas. Bellatin mostró el camino (vacío) y el lector puede continuar.

Primero hay que recalcar que la columna como fragmento es, a su vez, parte de una película que quedó fragmentada. Simón del desierto fue, al principio, un proyecto de largometraje, pero, por razones económicas, sólo dispuso de quince días para el rodaje y diez más para el montaje. El punto no está tanto en la columna como fragmento, sino en la fragmentariedad de la película: en la falta de presupuesto, en el apuro, en la filmación desprolija que consecuentemente va a tener como efecto posible el descuido de sus escenografías. En contra del criterio del director, el productor Gustavo Alatriste decidió presentar el material tal y como estaba, un total de cuarenta y dos minutos de metraje, a la Mostra de Venecia de 1965. Allí fue premiado, razón por la cual Buñuel se negó a proseguir con el proyecto primigenio, que incluía una escena bajo la nieve, peregrinaciones e incluso una visita (histórica) del emperador de Bizancio. ${ }^{29} \mathrm{El}$ carácter fragmentario de la película se aprecia mejor cuando leemos que, según lo entendió el propio Buñuel en términos casi bellatinianos, Simón del desierto bien podría ser integrada como relato en otra película como La vía láctea: "Hoy, me parece que Simón del desierto podría ser ya uno de los encuentros de los dos peregrinos de La Vía láctea en el sinuoso camino de Santiago de Compostela” ${ }^{30} \mathrm{La}$ columna, entonces, no expresa el tiempo mismo como los objetos de Proust según Tarkovski, pero se presenta como un residuo consecuente con la historia de cierto proceso creativo. Como señalamos, la película está fragmentada, inconclusa. Buñuel no pudo terminar su rodaje y, en el apuro, le proporcionó un final forjado por las circunstancias apremiantes. Satanás, que había tentado varias veces a Simón para que bajara de la columna, se le acerca una vez más y le anuncia que serán trasladados de ahí. Miran hacia arriba y un avión aparece surcando el cielo de modo anacrónico. Corte y la cámara planea por una ciudad moderna, llena de edificios y puentes. De ahí nos trasladan a una fiesta con guitarras eléctricas, con música de los sesenta. Simón y Satanás, interpretado por Silvia Pinal, están sentados en una mesa, vestidos con ropas para la ocasión. Simón, hastiado con el ruido, le dice a Satanás que se va a su casa, y este le replica: "Mejor no vayas, te vas a llevar un chasco. La habita otro inquilino". Este Simón sin lugar ni morada, en un encuentro insólito con gente de otro tiempo, ¿no es la misma historia que Bellatin rescata para nosotros en esa columna de otro tiempo rodeada de los bulliciosos habitantes de este presente? El propio Buñuel se describe en una situación como la de Simón al final de la película, descolocado como su columna olvidada:

Hoy el silencio es casi imposible, algo precioso que es dificilísimo de encontrar en alguna parte. Va usted, por ejemplo, al Polo a gozar del silencio y no me extrañaría que de pronto apareciera un esquimal en su trineo... y con una radio portátil y estruendosa. ¿Se imaginan ustedes lo que debe haber sido el silencio en la Edad Media? Salía usted del pueblo o de la ciudad y a los pocos pasos se hallaba el silencio, o los sonidos naturales,

imaginar el decorado de la historia. Pero si lo veía con tanta nitidez, es porque este instrumento prosaico resume todo un mundo sensible”. RANCIÈRE, J. El hilo perdido. Ensayos sobre la ficción moderna. Buenos Aires: Bordes Manantial, 2015 , p. 24. Para nosotros, Bellatin puede ver la columna porque ésta y su territorio ya tienen la forma de su escritura o porque, en los términos de Rancière, participan de un mismo régimen sensible o de visibilidad.

${ }^{29}$ SALVADOR VENTURA, F. Una imagen fílmica rigurosa de la Antigüedad tardía: “Simón del desierto” de Luis Buñuel. Habis, 38, 2007, pp. 329-343.

${ }^{30}$ MONTAUBAN, J., \& ARRIETA, E. C. Luis Buñuel: caminos de la intransigencia. Cuadernos Hispanoamericanos, (763), 2014, p. 92. 
que son maravillosos: el canto de los pájaros, el de las cigarras, o el rumor de la lluvia. Eso lo hemos perdido en nuestra época. Hay un instrumento infernal, que podría realmente haber inventado el diablo, o un enemigo de la humanidad: la guitarra eléctrica. Qué época diabólica la nuestra: la multitud, el smog, la promiscuidad, la radio, etc. Yo volvería encantado a la Edad Media, siempre que fuese antes de la Gran Peste del siglo XIV. ${ }^{31}$

Luego de que Bellatin señalara el vacío de relación entre la columna y su historia, dejó el espacio para que podamos reconectar la columna residual con la forma esencial de la película. En primer lugar, es fragmento de una película fragmentada: aunque la piedra no lleve inscripta en su accidentalidad la historia de su producción, su propia presencia, y su consecuente abandono, funcionan como índice de una producción cinematográfica descuidada y amputada con grandes problemas en su presente como para contemplar el destino de sus escenografías. Por otro lado, es también una réplica material del final de Simón en la película: el asceta pierde su lugar, no sólo la columna sino su contexto temporal y espacial, social y cultural. Además, como el anacoreta en la película, la propia columna se niega a ser trasladada a un nuevo lugar: el Palacio de Bellas Artes, donde en ese momento se realizaban homenajes a Buñuel, lo cual hubiera ligado y normalizado el destino de la columna con el nombre propio del cineasta español.

La reconexión de la piedra con el proceso creativo que le dio lugar es, por supuesto, una construcción y un descubrimiento del relato bellatiniano, que bordea creativamente los vacíos lacunarios de la Historia o del Tiempo en mayúsculas. De este modo, los reenvíos de este objeto singular a la película de Buñuel resultan de la localización de un vacío local que hace emerger un tiempo también local. Los reenvíos no están ahí en el texto, antes bien la retórica vaciada de Bellatin termina borrando o haciendo sospechosa toda referencia posible. Es este mismo vacío compartido por la escritura bellatiniana y el remanente de piedra el que invita a las conexiones porque "hace aparecer la historia donde no se la esperaba". ${ }^{32}$

Finalmente, este mismo vacío hace legible el vínculo particular del escritor con el cine o con determinadas películas: la trayectoria de la escritura bellatiniana no termina de relacionarse con aquéllas, deja que algunos temas e imágenes se alleguen a su trabajo pero sin convertirse en centro de la escritura. ${ }^{33}$ Se produce el encuentro con los anacoretas del cine, pero rápidamente se muestra el vacío que interrumpe ese roce, que lo borra como el viento se lleva las huellas en la arena, pero que es condición de posibilidad de la literatura bellatiniana. ${ }^{34}$

\footnotetext{
${ }^{31}$ COLINA y PÉREZ TURRENT Op. cit., p. 138.

${ }^{32}$ GOLDCHLUK, G. Op. cit., p. 48.

33 "Se trata, apenas, de un clinamen, una atracción recíproca: la del escritor respecto de un tono, un registro, un tema, unos caracteres, una música, un vocabulario, unas imágenes; y las del tono, el registro, el tema, los caracteres, la música y el vocabulario respecto del escritor". LINK, D. (2012). El escritor como “forma-de-vida”. Revista Landa, Vol 1 No 1, Universidade Federal de Santa Catarina, 2012, p. 3.

${ }^{34}$ La pedagogía implícita tanto en la Escuela Dinámica de Escritores, como en la relaciones de Bellatin con otras artes, y en especial con el cine, pueden formularse en términos de aquello que Deleuze llamó síntesis disyuntiva, donde un hiato deja de ser un medio de separación para ser un medio de comunicación y donde el encuentro entre dos heterogéneos no requiere la exclusión de los predicados de cada cosa en virtud de una identidad o de un concepto, sino que la disyunción se sostiene en tanto tal. "Dos cosas o dos determinaciones son afirmadas por su diferencia, es decir, no son objetos de afirmación simultánea sino en la medida en que su diferencia es también afirmada, es también afirmativa. No se trata en absoluto de una identidad de los contrarios, todavía inseparable en tanto que tal de un movimiento de lo negativo y de la exclusión. Se trata de una
} 


\section{Bibliografia}

BELlATIN, M. Señas particulares. Página 12. Entrevistador: Patricio Lennard. Disponible en https://www.pagina12.com.ar/diario/suplementos/libros/10-2356-2006-12-10.html, 2006. Acceso en 07 oct. 2021.

BELLATIN, M. (coord.) El arte de enseñar a escribir. Santiago de Chile: Fondo de Cultura Económica, 2006b.

BELLATIN, M. (Conrado Chang, entrevistador) Yo, creo, soy un señor que escribe. Buen salvaje, 2013.

BELLATIN, M. Algo que funciona sin funcionar. diecisiete, 7(7), 2015.

BELLATIN, M. Mario Bellatin se despoja de todo. La Nación, Buenos Aires, 2017.

BELLATIN, M. "En tu casa habita otro inquilino. El milagro de Buñuel. Revista de la Universidad de México, pp. 83-87. Disponible en https://www.revistadelauniversidad.mx/articles/beb7ab25-7777-4c51-b20d43815cda4904/en-tu-casa-habita-otro-inquilino, 2018. Acceso en 07 oct. 2021.

BENJAMIN, Walter. "Exhumar y recordar" ("Ausgraben und Erinnern“). Gesammelte Schriften, ed. de Rolf Tiedemann y Hermann Schweppenhäuser. Frankfurt am Main, Suhrkamp, tomo IV: Kleine Prosa. BaudelaireÜbertragungen; 400. Traducción de J. A. Ennis para uso de la cátedra de Filología Hispánica, UNLP.n, Walter. Disponible en https://filologiaunlp.files.wordpress.com/2012/03/exhumar-y-recordar.doc, 1991. Acceso en 07 oct. 2021.

CHERRI, C. Cine y literatura en América Latina. Las intervenciones de Mario Bellatin. Boletim de pesquisa nelic, florianópolis, v. 15, n. 24, 2015.

CHIRINOS, E.; MONTAUBAN, J. Luis Buñuel, caminos de la intransigencia. Cuadernos hispanoamericanos 763, 2014.

CUARTAS, J.P. El realismo cómico de Mario Bellatin: Shiki Nagaoka y el sentido errático. Jaimes, H. (Ed.). Mario Bellatin y las formas de la escritura. UNC Press Books, 2020.

DE LA COLINA, J.; PÉREZ TURRENT, T. Buñuel por Buñuel. Madrid: Plot Ediciones, 2002.

DE PEDRO, G. David Lynch: "Nunca he visto una película de Buñuel". El confidencial. Disponible en: https://www.elconfidencial.com/cultura/cine/2013-10-17/nunca-he-visto-una-pelicula-de-bunuel_42451/, 2013. Acceso en 07 oct. 2021.

DELEUZE, G. La imagen-tiempo. Estudios sobre cine 2. Barcelona: Paidós, 1987.

DELEUZE, G. Lógica del sentido, Madrid, Paidós, 1994.

distancia positiva de los diferentes: no ya identificar dos contrarios a lo mismo, sino afirmar su distancia como aquello que los remite uno a otro en tanto que 'diferentes”'. DELEUZE, G. Diferencia y repetición, Madrid, Paidós, 1994, p. 179. O en otros términos más concisos con respecto a la noción de síntesis disyuntiva: "La no-relación se convierte en una relación, la disyunción en una relación”. ZOURABICHVILI, F. El vocabulario de Deleuze, Buenos Aires, Atuel, 2007, p. 100. 
DELEUZE, G. Diferencia y repetición. Buenos Aires: Amorrortu, 2009.

ESPINOSA, L.; SFERCO, S. La fuerza discontinuante del olvido en la filosofía de Walter Benjamin. Heterotopías, 3(6), 1-24. Disponible en https://revistas.unc.edu.ar/index.php/heterotopias/article/view/31796/32660, 2020. Acceso en 07 oct. 2021.

GOLDCHLUK, G. El gran vidrio: un espejo imposible de identidades inexistentes plantado en medio del desierto literario. Deconstrucción del espacio literario en América Latina: 1996-2016. Universidad de Buenos Aires y Universidad de Poitiers, 2019.

LINK, D. El escritor como "forma-de-vida". Revista Landa, Vol 1 № 1, Universidade Federal de Santa Catarina, 2012. Disponible en https://revistalanda.ufsc.br/PDFs/link_landa_0.pdf. Acceso en 07 oct. 2021.

LÓPEZ ALFONSO, F. J. Mario Bellatin, el cuadernillo de las cosas difíciles de explicar. Universidad de Alicante, 2015.

RODLEY, C. Lynch por Lynch. Buenos Aires: El cuenco de plata, 2017.

RANCIÈRE, J. Bela Tarr. Después del final. Buenos Aires: El cuenco de plata, 2013.

RANCIÈRE, J. El hilo perdido. Ensayos sobre la ficción moderna. Buenos Aires: Bordes Manantial, 2015.

SALVADOR VENTURA, F. Una imagen fílmica rigurosa de la Antigüedad tardía: "Simón del desierto" de Luis Buñuel. Habis, 38, 2007.

TARKOVSKI, A. Esculpir en el tiempo. Reflexiones sobre el arte, la estética y la poética del cine. Madrid: Ediciones Rialp, S.A, (2002 [1985]).

TARR, B.; BEDOYA-WILSON, R. La extensión del mirar: entrevista a Béla Tarr. Ventana indiscreta $\mathrm{N}^{\circ} 20$. Lima, 2018.

VERGARA, P. El vacío como gesto: representación y crisis del sentido en la obra de Mario Bellatin. Revista Laboratorio, (2). Disponible en https://revistalaboratorio.udp.cl/index.php/laboratorio/article/view/101/95, 2010. Acceso en 07 oct. 2021.

ZOURABICHVILI, F. El vocabulario de Deleuze, Buenos Aires, Atuel, 2007. 